\title{
Several Variables Response to $2.2 \%$ Intra-Articular Injections of Hyaluronic Acid
}

\section{Abdullah BA*, Hamed GY and Rejab AF}

Department of Oral Medicine and Maxillofacial Surgery, Mosul University, Iraq

*Corresponding author: Basser Ali Abdullah, Department of Oral Medicine and Maxillofacial Surgery, Mosul University, Iraq, Tel: 009647508224680; Email: basserali30@yahoo.com

\section{Research Article}

Volume 5 Issue 6

Received Date: October 30, 2020

Published Date: November 13, 2020

DOI: $10.23880 /$ oajds-16000278

\section{Abstract}

Objectives of the research: to assess the effects of TMJ 2.2 hyaluronic acid injection on following TMJ pain, TMJ clicking, maximum opening capacity and lateral mandibular movements. This study include one hundred patients $(77 \mathrm{females}$ and 23males) whom complain from clicking and pain at their TMJ with or without limitation of mandibular movements. The age ranged between 9-65 years old. Hyaluronic acid 2.2\% were used for intra- articular injection unilaterally at the upper compartment of the most painful TMJ. Assessment of pain was done by using the visual analogue scale (0-10), the intensity of clicking was evaluated by stethoscope using basser clicking score, lateral movements were calculated by using ruler and recorded into special case sheet, and any complications that reported by the patients were recorded. These data were recorded before treatment and one, two, three weeks post injections, also one month after the last injection. SPSS (statistical package of social science) window 11.5 version was used for statistical investigation with chi square and paired $\mathrm{T}$ tests with $\mathrm{P} \leq 0.001$ as a significant value. The outcome of this study reveals that age cluster between (21-30) years was the most prevailing age, it signify (29\%) of the entire trial, whereas the age group over 50 years was the least represented age group, it signify $7 \%$, Female were presented in this study more often than males at a ratio of (3.3 -1). Regarding TMJ pain, there were significant differences $(\mathrm{P} \leq 0.001)$ before and after intra-articular drug administration. Significant differences $\mathrm{P} \leq 0.001$ were found in clicking scores means before and after intra-articular HA injections there were significant differences $\mathrm{P} \leq 0.001$ in maximum opening capacity means before and after TMJ injections. There were significant differences in both lateral left and right movements means $\mathrm{P} \leq$ 0.001 before and after TMJ injections of hyaluronic acid. This study conclude that HA $2.2 \%$ TMJ injection is an effective method in treating different TMJ diseases including temoporomandibular disorders, it reduce pain, clicking and improve mandibular motion, their effect persist even one month beyond last injection, it is effective, safe, painless, not costly, with no side effects like steroid, with no complications, usually no need to another drugs following injections like antibiotic and analgesic. We recommend that this modalities as the best treatment for TMDs. Also we conclude that females seek treatment more often than males at a ratio $3.3: 1$.

Keywords: Intra-articular injections; Hyaluronic acid

Abbreviations: TMD: Temporo-Mandibular Joint Disorder; TMJ: Temporomandibular Joint; HA: Hyaluronic Acid; LMW: Low Molecular Weight; HMW: High Molecular Weight.

\section{Introduction}

Temporomandibular joint disorder (TMD) is a broadly distributed illness at the world, it effect many population and usually pain is the main symptom with functional disturbance 
of the temporomandibular joint (TMJ), so the quality of the patient life will effected [1]. This disorders involve disc dislodgment and degenerative and/or inflammatory disorders. As having multifaceted etiology and different categorization, various reversible and surgical remedies were investigated in try to relieving pain as well repairing TMJ function [2]. Many reversible treatments include rest, nonsteroidal anti-inflammatory drugs, steroids, botox injections, oclussal splint, thermotherapy, coolant therapy, massage therapy, electrical stimulation therapy (transcutanuce electrical nerve stimulation) relaxant therapy \& EMG biofeedback were implicated [3]. Arthrocentesis among the alternatives surgical therapy which is indicated when there is no significant benefit to reversible management; it is an easy and minimally destructive method, generally aimed to wash out inflammatory elements from the synovial liquid [4]. The practice is done by administration of different drugs, such as sodium salt of hyaluronic acid, in trying to improve treatment efficacy [5]. Hyaluronic acid (HA) is a linear, hydrophilic, polyanionic high molecular weight polysaccharide mainly consists of repetitive bisaccharide units of glucuronic acid and $\mathrm{N}$-acetylglucosamine. HA is a normal element of joint synovial liquid, and is also found in the connective tissue [6]. This material is composed of a sodium hyaluronat which is a normal constituent of synovial fluid, the main function is providing a cushion against any shocks; HA has a lubricating of synovial joints and TMJ is one of these joints [7]. The tremendous mechanical and metabolic property of their molecule define it as the best drug for treatment of inflammatory disease of the joint [8].
HA also have anti- inflammatory effect, leading to abolish joint pain [9]. A number of researches have assess the efficiency of arthrocentesis with or without HA on pain and jaw motion in patients have TMDs. They found that the coupling of two treatments leading to better outcome [10]. At the sites of inflammation or in tissue injury, high molecular weight (HMW) HA may be disintegrated to low molecular weight (LMW) fragment through the activity of oxygen radicals or through enzymatic activity by hyaluronidase, $\beta$-glucuronidase and LMW fragments are able to trigger the innate immune defense, enhancing the production of various cytokines [11]. Because of the all positive characteristics, $\mathrm{HA}$ is preferable to be used in treatment of TMJ disorders as it possess tissue-healing properties, overcome the side effects of other drugs like steroid and safe in all patients [12]. TMJ HA injection is a harmless and efficient in reducing pain and sound, this procedure is easy, secure \& preferred by patients and no devices \& equipments are needed as in a bite plane construction as well no require for dentist chair, no complications related to this management like occlusal alteration as in interocclusal devices [13].

\section{Material and Methods}

This study include one hundred patients ( 77 females and 23males) whom complain from clicking and pain at their TMJ with or without limitation of mandibular movements. Those patients were referred to private clinic for diagnosis and treatment. Data information were collected and recorded in special case sheet Figure 1.

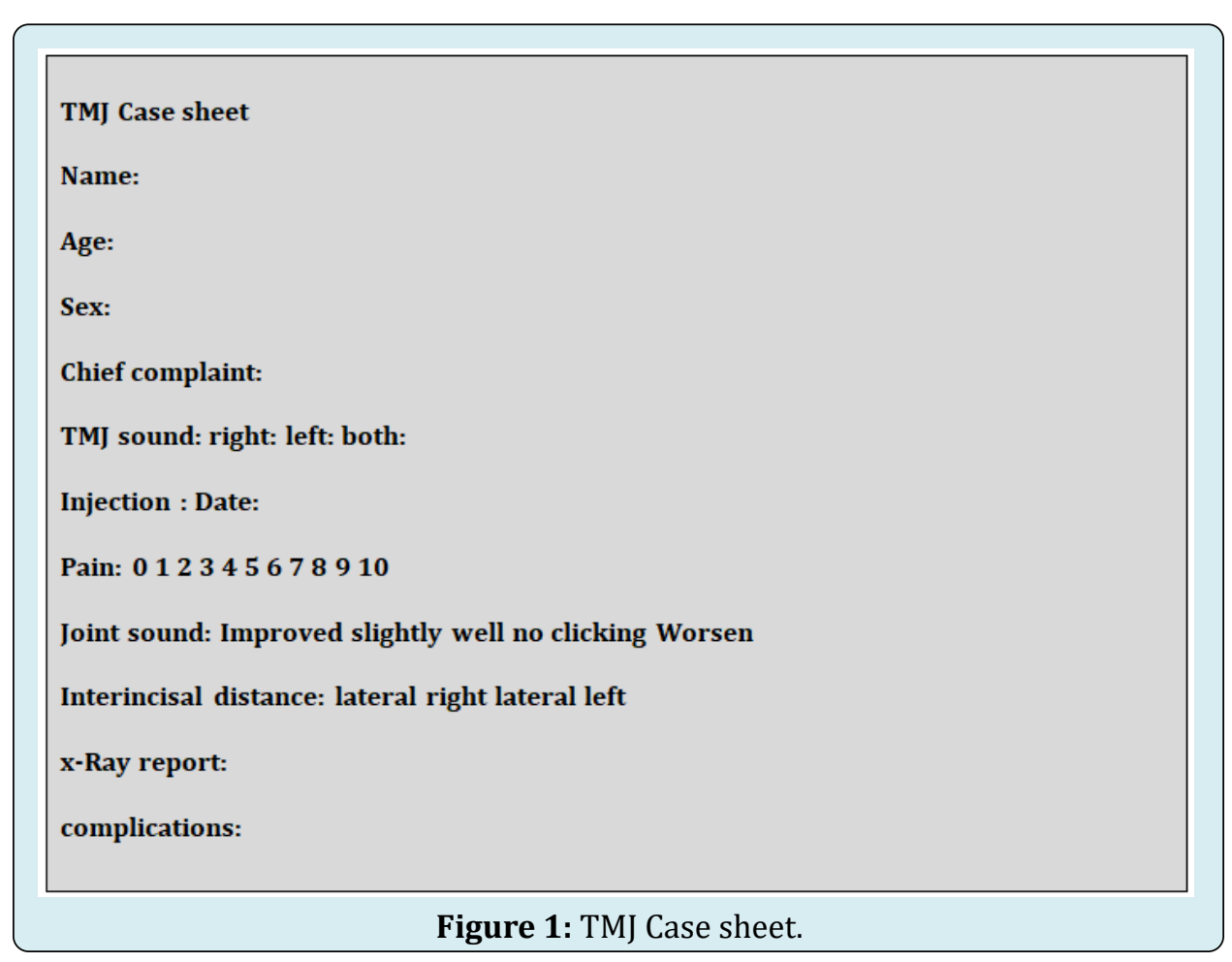


Panromic radiograph were taken, all patient selected having no bone diseases like Rheumatoid arthritis, osteoarthritis and psoriatic arthritis. Hyaluronic acid 2.2\% were used for intra- articular injection unilaterally at the upper compartment of the most painful TMJ. One specialist was doing these injections and follow up the patients to make standardization and to overcome bias. Lidocaine 2\% with adrenaline 1:100000 was used to anesthetized the auricotemporal nerve, after 3-5 minutes, a $0.6 \mathrm{ml}$ of $2.2 \%$ hyaluronic acid was injected into the superior compartment of the joint according to standardized technique, [13] then resistant exercise were done by operator, these injection's were done in three cycle at one week interval . Assessment of pain was done by using the visual analogue scale (0-10), the intensity of clicking was evaluated by stethoscope using basser clicking score [13] (1=slight improvement, 2=well improvement, $3=$ no clicking and 4=worsen). Maximum opening capacity (distance between upper and lower incisors), lateral movements (distance between upper and lower central incisors after lateral excursions) were calculated by using ruler and recorded into special case sheet (Figure 1) and any complications that reported by the patients were recorded. These data were recorded before treatment and one, two, three weeks post injections, also one month after the last injection .SPSS (statistical package of social science) window 11.5 version was used for statistical investigation with chi square and paired $\mathrm{T}$ tests with $\mathrm{P} \leq$

\subsection{1 as a significant value.}

\section{Results}

Table 1 reveal patients sharing in relation to the age and sex, the age group between (21-30) years was the most prevailing age, it signify (29\%) of the all patients, whereas the age group over 50 years was the least represented age group, it signify $7 \%$, female were presented in this study more often than males at a ratio of (3.3-1). Table 2 demonstrate the visual analogue scale before injection and one, two and three weeks post injections, and one month after the last injection, there were significant differences ( $\mathrm{P} \leq 0.001)$ before and after intra-articular injections. The clicking sound intensity means before and after TMJ injections of hyaluronic acid were evaluated numerically as follow (1=slight improvement, 2=well improvement, $3=$ disappearance of clicking and 4=worsen), there were considerable differences $\mathrm{P} \leq 0.001$ in clicking scores means before and after intra-articular injections as shown in Table 3 . Table 4 reveal the maximum opening capacity means before and after hyaluronic acid injections, there were valuable differences $\mathrm{P} \leq 0.001$ in maximum opening capacity means before and after TMJ injections. There were considerable differences in both lateral left and right movements means $\mathrm{P} \leq 0.001$ before and after TMJ injections of hyaluronic acid as demonstrated in Table 4.

\begin{tabular}{|c|c|c|c|c|c|c|}
\hline \multirow{2}{*}{ Age/Years } & \multicolumn{2}{|c|}{ Male } & \multicolumn{2}{c|}{ Female } & \multicolumn{3}{c|}{ Total } \\
\cline { 2 - 8 } & No & \% & No & \% & No & \% \\
\hline $9-20$ & 7 & 30 & 21 & 27 & 28 & 28 \\
\hline $21-30$ & 6 & 26 & 23 & 29 & 29 & 29 \\
\hline $31-40$ & 4 & 17 & 15 & 19 & 19 & 19 \\
\hline $41-50$ & 4 & 17 & 13 & 16.8 & 17 & 17 \\
\hline$\geq 51$ & 2 & 10 & 5 & 6.4 & 7 & 7 \\
\hline
\end{tabular}

Table 1: Patients distribution according to age group and sex.

\begin{tabular}{|c|c|c|c|c|c|c|c|}
\hline Visual Analogue Scale & Min & Max & Mean & Std Dev & Relation & $\mathbf{X}^{2}$ & Significance \\
\hline O & 2 & 10 & 7.62 & 2.08 & & & \\
\hline A & 2 & 10 & 7.59 & 2.07 & O-A & 53.7 & 0 \\
\hline B & 0 & 10 & 4.8 & 2.29 & O-B & 72.9 & 0 \\
\hline C & 0 & 7 & 2.34 & 1.40 & O-C & 80.4 & 0 \\
\hline D & 0 & 10 & 1.52 & 1.57 & O-D & 202.4 & 0 \\
\hline
\end{tabular}

$\mathrm{O}=$ Base line data before injection, $\mathrm{A}=$ one week after injection, $\mathrm{B}=$ two weeks after injection, $\mathrm{C}=$ three weeks after injection, $\mathrm{D}$ = one month after last injection, Min = minimum, Max = maximum, StdDev = slandered deviation, $\mathrm{X} 2=\mathrm{CHI}$ square test.

Table 2: Visual analogue scale means pre and post intra-articular injections. 
Open Access Journal of Dental Sciences

\begin{tabular}{|c|c|c|c|c|c|}
\hline Clicking score & Mean & Std. Dev. & Relation & $\mathbf{X}^{\mathbf{2}}$ & Significance \\
\hline O & 5.0 & 0.0 & & & \\
\hline A & 1.2 & 0.477 & O-A & 108.74 & 0.000 \\
\hline B & 2.41 & 0.766 & O-B & 28.340 & 0.000 \\
\hline C & 2.66 & 0.654 & O-C & 82.160 & 0.000 \\
\hline D & 2.74 & 0.596 & O-D & 106.64 & 0.000 \\
\hline
\end{tabular}

Table 3: TMJ clicking score means before and after intra-articular injections.

\begin{tabular}{|c|c|c|c|c|c|c|}
\hline \multicolumn{2}{|l|}{ Variables } & Mean & Std. Dev. & Relation & Paired T test & Significance \\
\hline \multirow{5}{*}{$\begin{array}{l}\text { Maximum open- } \\
\text { ing capacity }\end{array}$} & 0 & 36.39 & 9.01 & & & \\
\hline & A & 36.30 & 8.99 & O-A & 0.994 & 0.000 \\
\hline & $\mathrm{B}$ & 39.26 & 8.73 & O-B & 0.895 & 0.000 \\
\hline & $\mathrm{C}$ & 39.85 & 8.34 & O-C & 0.868 & 0.000 \\
\hline & $\mathrm{D}$ & 38.36 & 8.72 & O-D & 0.627 & 0.000 \\
\hline \multirow{5}{*}{$\begin{array}{c}\text { Lateral Right } \\
\text { Movement }\end{array}$} & 0 & 6.20 & 2.24 & & & \\
\hline & $\mathrm{A}$ & 6.36 & 2.18 & O-A & 0.931 & 0.000 \\
\hline & $\mathrm{B}$ & 7.25 & 2.19 & O-B & 0.829 & 0.000 \\
\hline & $\mathrm{C}$ & 8.20 & 2.11 & $\mathrm{O}-\mathrm{C}$ & 0.648 & 0.000 \\
\hline & $\mathrm{D}$ & 8.21 & 2.08 & O-D & 0.562 & 0.000 \\
\hline \multirow{5}{*}{$\begin{array}{c}\text { Lateral Left Move- } \\
\text { ment }\end{array}$} & 0 & 6.21 & 2.32 & & & \\
\hline & $\mathrm{A}$ & 6.27 & 2.37 & O-A & 0.962 & 0.000 \\
\hline & $\mathrm{B}$ & 7.60 & 2.57 & O-B & 0.876 & 0.000 \\
\hline & $\mathrm{C}$ & 8.88 & 1.94 & $\mathrm{O}-\mathrm{C}$ & 0.583 & 0.000 \\
\hline & $\mathrm{D}$ & 8.81 & 1.98 & O-D & 0.578 & 0.000 \\
\hline
\end{tabular}

Table 4: Maximum opening capacity means in millimeters pre and post injections.

\section{Discussion}

The first uses of HA in TMJ disorders since 20 years ago [14], There is a continuous debate in the studies concerning the advantages of utilizing HA administration in the management of TMD [1], as well to establishing an ideal basis and procedure to abolish pain and retain function $[15,16]$. TMDs are a variety cluster of disorder disturbing the muscles of mastication or TMJ, sometime both of them will be effected [17]. This disease is manifested by typically described triad of clinical features: (TMJ) and/or muscle pain, TMJ clicking and limitation or deflection in the path of mouth opening [18]. TMD is the second most frequent cause of orofacial pain after dental pain, about $20 \%$ to $30 \%$ of the adult population are affected to some degree [19], however the percentage of patients who essentially need management is about $16 \%$ [20,21]. Internal derangement of the TMJ like displacements of disc and degenerative joint diseases represent majority of TMD patients [22] and could be treated with several procedures that aimed to alleviate pain and promote function [23]. One of them is administration of sodium hyaluronate which getting interest as successful procedures, ether lonely or with joint lavage [24]. Hyaluronic acid have a considerable role in preserving TMJ homeostasis, it provides protection against shocks due to the high viscosity and elasticity of the synovial fluid. HA It exhibits anti-inflammatory and analgesic effects and trigger tissue repairing process via synthesis of endogenous acid by the synovial cells $[25,26]$. Irregularities of the joint lubrication system may sharing and lead to TMDs [27,28], thus a HA providing a basis for the visco-supplementation in patients with TMJ internal derangements and inflammatorydegenerative disorders. But although the number of researches which were established on this ground, there is little evidence-based data gleaned by a systematic review of the literature [29].

This study were done to evaluate the effects of $2.2 \%$ 


\section{Open Access Journal of Dental Sciences}

HA injections on TMJ pain, TMJ sounds and mandibular movements in 100 patients with one month follow up. In this study there were valuable differences $(\mathrm{p} \leq 0.001)$ in VAS scores before and after TMJ injections of HA and this is consistent with other studies $[30,31]$. The mechanism of pain in the tempromandibular joint is not obvious. Dick displacement, Synovitis, osteoarthritis and chondromalacia are thought to sharing to this illness. The investigation of synovial fluid give significant qualitative and quantitative information of the inflammatory reaction [32]. This reaction could be caused by internal and external trauma, resulting in hypoxia and reperfusion injury with chemotaxis of mononuclear cells, polymorphonuclear cells, and lymphocytes, aiding to liberation of cytokines, such as interleukin (IL)-1, IL-8, tumor necrosis factor- $\alpha$, interferon- $\gamma$ platelet activating factor, fibroblast growth factor, vascular endothelial growth factor, and vascular adhesion molecules. Consequently resulting in formation of reactive species, such as hydroxyl radicals, peroxynitrite anion, myeloperoxidase, hydroxide anion, peroxide, superoxide anion, matrix metalloproteinases, and ferrous ions, which are responsible for tissue injury and result in the disintegration of elastin, collagen, and proteoglycan. The inflammatory reaction moreover results in manufacturing of anti-inflammatory cytokines, such as IL-4, IL-6 IL-10, IL-12 and IL-13, and these inflammatory response persist till the cause is recognized and treated [33]. HA possess analgesic properties through their effect on the nerve endings of the TMJ. This action occur at mechanosensitive stretch-activated ion channels, HA binding extensively reduced these channel activity which efficiently block the response pain stimulus, low molecular weight HA was seen to be less efficient in blocking pain response than the high one. HA reduces the action of joint nociceptors, which provides pain reduction within the joint. HA concentration influence the sensitive nociceptive ending within the joint tissue, leading to drop in pain response exhibited by these ending [33]. Disappearance or improvements of TMJ sounds were found after intra-articular injections of HA as showed in Table 3, and this result agrees with other study Morey Mas MA, et al. [3] and inconsistent with Bergstrand, et al. study [34] whom found no significant differences in joint sound after 4 years follow up, The disappearance or improvements of TMJ sounds can be explained by the viscoelastic action of hyaluronic acid. HA have mechanical action by lubricating the joint and finally reduce wear of joint, with a diminution of the intra-articular friction.

Hyaluronic acid also decrease the intensity of inflammatory elements, thus contributing to abolish pain in the joint [9]. The injection of hyaluronic acid (HA) into the joint has been assumed to decrease inflammation by possing anti-inflammatory properties as well, hyaluronic acid is believed to intensify viscosity in the intra-articular space and lubricating of the joint [32]. Hyaluronic acid plays a major role in preserving intra-articular homeostasis; it provides viscosity and elasticity of the synovial liquid, leading to shocks absorption in addition performing lubricating, antiinflammatory and analgesic actions and activate tissue repair process, as well physiological action on the synthesis of endogenous acid by the synovial cells [35]. Improvements in mandibular movements in vertical and horizontal directions were found in this research, as there were considerable differences $(\mathrm{P} \leq 0.001)$ in maximum opening capacity, lateral right and left movements before and after injections of HA and one month later as seen in Tables 4-6, and this result are consistent with other study Manfredini D, et al. [15]. HA is a universal mucopolysaccharide that is present normally in many structures. It potentially reduce reactive oxygen species, cytokine production, vascular permeability, and polymorph migration. The subsequent result is enhanced joint mobility and reduce inflammation and pain [36].

\section{Complication}

Three patients were suffering from temporary visual discomfort following local anesthetics injection at the injected side, and these complication related to facial nerve anesthesia rather than hyaluronic acid injection.

New concept in this study:

a. Utilize of $2.2 \%$ of sodium hyaluronate instead of $1 \%$.

b. Follow up 1month after last injection.

\section{Conclusion}

HA 2.2\% TMJ injection is an effective method in treating different TMJ diseases including temoporomandibular disorders, disc displacement with and without reduction, it reduce pain, clicking and improve mandibular motion, their effect are obvious even one month beyond last injection, it is effective, safe, painless, not costly, with no side effects like steroid, with no complications, usually no need to another drugs following injections like antibiotic and analgesic. We recommend that this modalities as the best treatment option for TMDs. Also we conclude that females seek treatment more often than males at a ratio 3.3:1.

\section{Suggestion}

a. Long term study with large sample.

b. Study the platelets rich fibrin on TMJ disorder.

\section{References}

1. Emes Y, Arpinar IS, Oncu B, Aybar B, Aktas I, et al. (2014) The next step in the treatment of persistent temporomandibular joint pain following arthrocentesis: a retrospective study of 18 cases. J Craniomaxillofac Surg 42(5): 65-69.

2. Manfredini D, Favero L, Del Giudice A, Masiero S, Stellini 
E, et al. (2013) Axis II psychosocial findings predict effectiveness of TMJ hyaluronic acid injections. Int J Oral Maxillofac Surg 42(3): 364-368.

3. Morey Mas MA, Caubet Biayna J, Varela Sende L, Iriarte Ortabe JI (2010) Sodium hyaluronate improves outcomes after arthroscopic lysis and lavage in patients with Wilkes stage III and IV disease. J Oral Maxillofac Surg 68: 1069-1074.

4. Aktas I, Yalcin S, Sencer S (2010) Prognostic indicators of the outcome of arthrocentesis with and without sodium hyaluronate injection for the treatment of disc displacement without reduction: a magnetic resonance imaging study. Int J Oral Maxillofac Surg 39(11): 10801085.

5. Guarda Nardini L, Rossi A, Arboretti R, Bonnini S, Stellini E, et al. (2015) Singleor multiple-session viscosupplementation protocols for temporomandibular joint degenerative disorders: a randomized clinical trial. J Oral Rehabil 42(7): 521-528.

6. Alpaslan GH, Alpaslan C (2001) Efficacy of temporomandibular joint arthrocentesis with and without injection of sodium hyaluronate in treatment of internal derangements. J Oral Maxillofac Surg 59(6): 613-618.

7. Triantaffilidou K, Venetis G, Bika O (2013) Efficacy of hyaluronic acid injections in patients with osteoarthritis of the temporomandibular joint A comparative study. J Craniofac Surg 24(6): 2006-2009.

8. Sato S, Oguri S, Yamaguchi K, Kawamura H, Motegi $\mathrm{K}$ (2001) Pumping injection of sodium hyaluronate for patients with non-reducing disc displacement of the temporomandibular joint: two year follow-up. J Craniomaxillofac Surg 29(2): 89-93.

9. Hepguler S, Akkoc YS, Pehlivan M, Ozturk C, Celebi G, et al. (2002) The efficacy of intra-articular sodium hyaluronate in patients with reducing displaced disc of the temporomandibular joint. J Oral Rehabil 29(1): 8086.

10. Tuncel U (2012) Repeated sodium hyaluronate injections following multiple arthrocenteses in the treatment of early stage reducing disc displacement of the temporomandibular joint: a preliminary report. J Craniomaxillofac Surg 40(8): 685-689.

11. Jiang DJ, Liang J, Fan S (2005) Regulation of lung injury and repair by Toll-like receptors and hyaluronan. Nat Med 11(11): 1173-1179.
12. Hamed GY (2015) The Efficacy of Hyaluronic Acid Spray in Treatment of Recurrent Aphthus Ulcer. International Journal of Enhanced Research in Science Technology \& Engineering 4(4): 82-86.

13. Abdullah BA (2014) Effectivness of TMJ intra-articular injections of Sodium Hyaluronate on clicking in patients with temporomandibular disorders (Clinical Study). International Journal of Enhanced Research in Science Technology \& Engineering 3: 451-459.

14. Kopp S, Carlsson G, Haraldson T, Wenneberg B (1987) Long-term effect of intraarticular injections of sodium hyaluronate and corticosteriod on temporomandibular joint arthritis. J Oral Maxillofacial Surg 45(11): 929-935.

15. Manfredini D, Rancitelli D, Ferronato G (2012) Arthroscentesis with or without additional drugs in temporomandibular joint inflammatory-degenerative disease: comparison of six treatment protocols. J Oral Rehabil 39(4): 245-251.

16. Guarda Nardini L, Ferronato G, Manfredini D (2012) Twoneedle vs. single-needle technique for TMJ arthrocentesis plus hyaluronic acid injections: a comparative trial over a six month follow up. Int J Oral Maxillofac Su 41(4): 506513.

17. McNeill C (1997) Management of temporornandibular disorders: concepts and controversies. J Prosthet Dent 77(5): 510-522.

18. Friction JR, Schiffmann EL (1995) Epidemiology of temporomandibular disorders. In: Friction JR \& Dubner R, (Eds.), Orofacial pain and temporomandibular disorders. New York, Raven Press, Ltd., pp: 1-14.

19. Al Jundi MA, John MT, Seiz JM, Szentperry A, Kuss O (2008) Meta-analysis of treatment need for temporomandibular disorders in adult nonpatients. J Orofac Pain 22(2): 97107.

20. Manfredini D, Guarda Nardini L (2010) TMD epidemiology and classification. In: Manfredini D, (Eds.), Current concepts on temporomandibular disorders. Berlin: Quintessence Publishing.

21. Okeson JP (2008) The classification of orofacial pains. Oral Maxillofac Surg Clin North Am 20(2): 133-144.

22. Nitzan DW, Benoliel R, Heir G, Dolwick F (2008) Pain and dysfunction of the temporomandibular joint. In: Sharav E \& Benoliel R, (Eds.), Orofacial pain and headache. Philadelphia: Mosby-Elsevier, Philadelphia, pp: 149-192.

23. Guarda Nardini L, Ferronato G (2010) TMJ arthrocentesis. In: Manfredini D, (Eds.), Current concepts on 


\section{Open Access Journal of Dental Sciences}

temporomandibular disorders. Berlin: Quintessence Publishing.

24. Nitzan DW, Nitzan U, Dan P, Yedgar S (2001) The role of hyaluronic acid in protecting surface-active phospholipids from lysis by exogenous phospholipasc A2. Reumato 40: 336-340.

25. Casconc P, Fonzi Dagger L, Aboh IV (2002) Hyaluronic acid's biomechanical stabilization function in the temporomandibular joint. J Craniofac Surg 13(6): 751754 .

26. Nitzan DW (2001) The process of lubrication impairment and its involvement in temporomandibular joint disk displacement: a theoretical concept. J Orul Maxillofac Surg 59(1): 36-45.

27. Nitzan DW, Kreiner B, Zeltser B (2004) TMJ lubrication system: its effect on the joint function, dysfunction, and treatment approach. Compen Contin Educ Dent 25(6): 443-444.

28. Shi Z, Guo C, Awad M (2003) Hyaluronate for temporomandibular joint disorders. Cochrane Database Syst Rev Issue 1: CD002970.

29. Gencer ZK, Ozkiris M, Okur A, Korkmaz M, Saydam L (2014) A comparative study on the impact of intraarticular injections of hyaluronic acid, tenoxicam and betametazon on the relief of temporomandibular joint disorder complaints. J Craniomaxillofac Surg 42(7): 1117-1121.

30. Bjørnland T, Gjaerum AA, Møystad A (2007) Osteoarthritis of the temporomandibular joint: an evaluation of the effects and complications of corticosteroid injection compared with injection with sodium hyaluronate. J Oral Rehabil 34(8): 583-589.

31. Bouloux GF (2009) Temporomandibular joint pain and synovial fluid analysis: A review of the literature. J Oral Maxillofac Surg 67(11): 2497.

32. Bouloux GF, Chou J, Krishnan D, Aghaloo T, Kahenasa N (2017) Is Hyaluronic Acid or Corticosteroid Superior to Lactated Ringer Solution in the Short-Term Reduction of Temporomandibular Joint Pain After Arthrocentesis? Part 1. J Oral Maxillofac Surg 75(1): 52-62.

33. Altman RD, Manjoo A, Fierlinger A, Niazi F, Nicholls M (2015) The mechanism of action for hyaluronic acid treatment in the osteoarthritic knee: A systematic review. BMC Musculoskelet Disord 16: 321.

34. Bergstrand S, Ingstad H, Moystad A, Bjornland T (2019) Long-term effectiveness of arthroscentesis with and without hyaluronic acid injection for treatment of temoromandibular joint osteoethritis J Oral Science 61(1): 82-88.

35. Kopp S, Wenneberg B, Haraldson T, Carlsson GE (1985) The short-term effect of intra-articular injections of sodium hyaluronate and corticosteroid on temporomandibular joint pain and dysfunction. J Oral Maxillofac Surg 43(6): 429-435.

36. Alpaslan C, Bilgihan A, Alpaslan GH, Guner B, Yis OM, et al. (2000) Effect of arthrocentesis and sodium hyaluronate injection on nitrite, nitrate, and thiobarbituric acidreactive substance levels in the synovial fluid. Oral Surg Oral Med Oral Pathol Oral Radiol Endod 89(6): 686-690. 